\title{
FITOTOXIDADE DE HERBICIDAS APLICADOS EM PÓS-EMERGÊNCIA NA FASE INICIAL DA CULTURA DO MILHO ${ }^{1,2}$
}

\author{
PAULO C. MAGALHÃES ${ }^{3}$, JOÃo B. DA SILVA ${ }^{4}$ e FREDERICO O. M. DURÃES ${ }^{3}$
}

\section{RESUMO}

A aplicação de herbicidas em pósemergência inicial e em pós-emergência dirigida pode causar injúrias às plantas de milho, quando estas são atingidas por produtos não totalmente seletivos. Como esses herbicidas são basicamente bloqueadores de processos metabólicos, surge a dúvida de quais serão os efeitos dessas injúrias na produção final de grãos de milho. Assim, o objetivo deste trabalho foi estudar o efeito da fitotoxidade causada pela aplicação de herbicidas na fase inicial e na pós-emergência tardia da cultura e o seu efeito na produção de grãos. Foi utilizado o híbrido BRS 3123, em 12 tratamentos repetidos 4 vezes. Esses tratamentos consistiram da aplicação dos seguintes herbicidas: cyanazine + simazine + assist, aplicados nos estádios de crescimentos de 4 e 6 folhas e paraquat + extravon e ametryn + assist, aplicados no estádio de 12 folhas, em jato dirigido. Foram incluídos também testemunhas com e sem capinas, além dos tratamentos com retirada mecânica das folhas do $1^{\circ}$ e do $1^{\circ}$ ao $3^{\circ}$ pares de folha. Foram avaliados: área foliar, matéria seca, teor de clorofila nas folhas, altura da planta e da inserção de espigas, diâmetro do colmo, índice de espigas, peso de 1000 grãos e produção de grãos. Observou-se que no no primeiro ano agrícola (94/95), as variáveis de crescimento não foram afetadas pelos tratamentos, ao passo que no ano seguinte, o melhor desenvolvimento das plantas foi obtido com a aplicação de cyanazine + simazine, enquanto que paraquat + extravon, ametryn + assist e testemunha sem capina, (devido ao efeito de matocompetição), resultaram nos piores tratamentos até a floração do milho. A maior produção de espigas e grãos no primeiro ano foi obtida com o tratamento cyanazine + simazine + assist, enquanto que, no segundo ano, paraquat + extravon e ametryn + assist proporcionaram as maiores produções, apesar das injúrias observadas na área foliar.

Palavras chave: Injúria, fotoassimilados, Zea mays.

\section{ABSTRACT \\ Toxicity of herbicides post emergents at maize crop initial phase}

Herbicide application at post emergence stage may cause injuries to maize plants, when these plants are reached randomly by non selective products. Since these herbicides act basically blocking metabolic processes, the question which has been raised is concerned what are the effects that these injuries will result in the grain production. Therefore the objective of this work was to study the phytotoxic effects caused by the application of herbicides at the initial phase and at late post emergency stage of the crop and its effect in the grain production. It was used the hybrid BRS 3123, with 12 treatments in 4 replications. These treatments were performed by the combination of the application of the following herbicides: cyanazine + simazine with

\footnotetext{
Recebido para publicação em 28/06/99 e na forma revisada em 13/09/99.

2 Trabalho desenvolvido pela Embrapa Milho e Sorgo. Rod. MG 424, Km 65, C.P. 151, CEP: 35 701-970, Sete Lagoas/MG.

3 Pesquisadores, PhD, Embrapa Milho e Sorgo - Sete Lagoas/MG.

${ }^{4}$ Consultor Autônomo, Ph.D., Sete Lagoas/MG.
} 
or without Assist, applied at growth stages of 4 and 6 corn leaves; paraquat + extravon and ametryn + Assist, applied as directed spray at the growth stage of 12 leaves. In addition, it was included the treatment with and without hoeing and the defoliation of first and third pair of leaves at the 12 leaf stage. It was evaluated: leaf area, dry matter, chlorophyl content in the leaves, plant height, ear height, ear index, weight of ears and grains. The first year (1994/95) the variables of growth were not affected by the treatments, whereas at the following year (1995/96), the best development of plants was obtained by the

\section{INTRODUÇ̃̃O}

Com o aumento da área plantada em milho no Brasil (Milho, 1998) e a adoção das tecnologias disponíveis, a utilização de herbicidas em pós-emergência na cultura do milho tem se tornado cada vez mais freqüente (Silva et al. 1998). No entanto, herbicidas não totalmente seletivos podem causar injúrias às plantas de milho, quando estas são involuntariamente atingidas. Como esses agentes químicos são basicamente bloqueadores de processos metabólicos, entre os quais a fotossíntese, a questão que surge é: quais serão os efeitos dessas injúrias no processo produtivo da cultura? A área foliar verde do milho é tida como a principal fonte de fotoassimilados para a planta (Magalhães et al., 1995 e Magalhães \& Jones, 1990a) e, segundo Fancelli (1998), uma perda nessa fonte poderá refletir no desenvolvimento da planta e na produção de grãos.

Resultados experimentais em milho tem demonstrado que, entre as folhas superiores e inferiores, as primeiras tem uma contribuição mais significativa para a produção de grãos (Allison \& Watson, 1966). Soma-se a isso o fato do milho conter uma considerável reserva de fotoassimilados no colmo (Duncan et al., $1967 \mathrm{e}$ Tollenaar \& Daynard, 1978b), os quais podem ser translocados para os grãos na fase de enchimento (Adelana \& Milbourn, 1972; Jones \& Simmons, 1983 e Lucas, 1981). application of cyanazine + simazine, and the worst treatments were paraquat + extravon, ametryn + assist and the plot without hoeing. The greater production of ears and grains at first year came from the treatment cyanazine + simazine + assist , whereas in the second year, paraquat + extravon and ametryn + Assist resulted in the best yield. Application of herbicides in post emergence at the initial phase of the crop, besides providing a good weed control, did not affect the development of maize plant.

Key words: Injury, carbohydrates, recovery, Zea mays.

Não existem atualmente dados suficientes na literatura para responder questionamentos relativos a uma possível queda na produção de grãos quando as plantas de milho são atingidas por herbicidas não totalmente seletivos. Dentro deste contexto o objetivo deste trabalho foi avaliar o efeito da fitotoxidade causada pela aplicação de herbicidas na fase inicial da cultura e o seu efeito na produção de grãos.

\section{MATERIAL E MÉTODOS}

$\mathrm{O}$ ensaio foi conduzido na área experimental do Centro Nacional de Pesquisa de Milho e Sorgo (CNPMS), Sete Lagoas - MG, durante dois anos agrícolas (1994/95 e 1995/96). O solo utilizado foi um latossolo vermelho escuro, fase cerrado, textura argilosa, adubado de acordo com a recomendação da análise do solo. Para o ano agrícola 1994/95 foi aplicado $350 \mathrm{~kg} / \mathrm{ha}$ da fórmula 4-30-16 + zinco e $45 \mathrm{~kg} / \mathrm{ha}$ de $\mathrm{N}$ em cobertura, no ano seguinte $400 \mathrm{~kg} / \mathrm{ha}$ da fórmula 4-14-8 + zinco e $45 \mathrm{~kg} / \mathrm{ha}$ de $\mathrm{N}$ em cobertura. A área experimental foi irrigada sempre que necessário baseando-se em leituras de tensiômetros instalados previamente a 20 e $40 \mathrm{~cm}$ de profundidade. Adotou-se o limite de -0.07 MPa como o momento da irrigação (Resende et al., 1992). Foi utilizado o milho híbrido triplo BRS 3123, nos seguintes tratamentos:

1. Cyanazine + Simazine + assist (pós: 4 folhas)

2. Cyanazine + Simazine (pós: 4 folhas) 
3. Cyanazine + Simazine + assist (pós: 6 folhas)

4. Cyanazine + Simazine (pós: 6 folhas)

5. Paraquat+Extravon (jato no $1^{\circ}$ par de folhas, estádio de 12 folhas)

6. Paraquat+Extravon (jato no $3^{\circ}$ par de folhas, estádio de 12 folhas)

7. Ametryn + Assist (jato no $1^{\circ}$ par de folhas, estádio de 12 folhas)

8. Ametryn + Assist (jato no $3^{\circ}$ par de folhas, estádio de 12 folhas)

9. Retirada manual do $1^{\circ}$ par de folhas (estádio de 12 folhas)

10. Retirada manual do $1^{\circ}$ ao $3^{\circ}$ pares de folhas (estádio de 12 folhas)

11. Testemunha com capina

12. Testemunha sem capina

As doses e produtos comerciais utilizados

no ensaio foram: Blazina SC (cyanazine + simazine) a 6,4 1/ha; Gramoxone (paraquat) a 2 1/ha; Gesapax (ametryn) a 3 1/ha; Assist a 0,5\% $\mathrm{v} / \mathrm{v} ; \mathrm{e}$, Extravon a $0,1 \% \mathrm{v} / \mathrm{v}$.

A aplicação dos tratamentos foi estabelecida em diferentes estádios de desenvolvimento da cultura (4, 6 e 12 folhas completamente desenvolvidas). A pulverização nos estádios iniciais foi realizada em área total, utilizando-se um pulverizador tipo monociclo equipado com barra de oito bicos APJ-110.R, pressão de $2,75 \mathrm{Kgf} / \mathrm{cm}^{2}$, com uma vazão de 240 1/ha. A pressão de pulverização foi obtida através de um cilindro de $\mathrm{CO}_{2}$ e controlada por um manômetro de baixa pressão. As condições climáticas para ano agrícola 1994/95, no período da aplicação (estádios de 4 e 6 folhas) apresentaram-se com uma temperatura média em torno de $30.5^{\circ} \mathrm{C}$ e umidade relativa de $63 \%$. Para $\mathrm{o}$ ano seguinte, no mesmo período foram registrados $29.5^{\circ} \mathrm{C}$ de temperatura e umidade relativa de $68 \%$. No estádio de 12 folhas, a pulverização foi feita no centro das entrelinhas com um pulverizador costal tipo mochila, tanque de $10 \mathrm{~L}$, pressurizado a $\mathrm{CO}_{2}$ e munido de um bico TF-VS3 (floodjet), pressão de $2,00 \mathrm{Kgf} / \mathrm{cm}^{2}$, com uma vazão de 295 1/ha, ajustando-se a altura do bico para atingir-se o primeiro par de folhas baixeiras do milho (tratamentos 5 e 7 ) e o terceiro par de folhas (tratamentos 6 e 8). As condições climáticas relativas a temperatura e umidade relativa para essa época de aplicação foram respectivamente $29.1^{\circ} \mathrm{C}$ e $75 \%$ (ano agrícola 1994/95) e $29.0^{0} \mathrm{C}$ e $79 \%$ (ano agrícola 1995/96). Para evitar-se o efeito da matocompetição sobre a cultura, mascarando o efeito de injúrias químicas sobre a produtividade, todas as parcelas, com exceção das parcelas testemunhas sem capina (tratamento 12), foram capinadas manualmente sempre que necessário. Neste trabalho, não se cogitou o efeito dos tratamentos químicos sobre as plantas daninhas.

O delineamento experimental foi de blocos ao acaso com 12 tratamentos e quatro repetições. Na época do florescimento foram avaliados as seguintes características: altura da planta, área foliar, matéria seca das plantas e teor de clorofila nas folhas. No final do ciclo da cultura: altura final da planta, altura de inserção das espigas, diâmetro do colmo, peso de espigas, peso de 1000 grãos e produção de grãos. A parcela experimental foi constituída de 4 linhas de 9 metros de comprimento espaçadas de $0.90 \mathrm{~m}$ com cinco sementes por metro, sendo que para a área útil foi considerada as duas fileiras centrais de $8 \mathrm{~m}$ de comprimento, abandonando-se $0.50 \mathrm{~m}$ nas cabeceiras. Os dados foram submetidos a análise de variância e as médias separadas pelo teste de Tukey. Para discussão dos resultados nos dois anos agrícolas foram selecionados dois componentes de crescimento (área foliar e matéria seca das plantas) e dois componentes de produção (peso de espigas e peso de grãos), corrigidos para a umidade padrão de $13 \%$.

\section{RESULTADOS E DISCUSSÃO}

No ano agrícola 1994/95, as variáveis relacionadas ao crescimento e desenvolvimento das plantas não apresentaram diferenças estatisticamente significativas entre os diversos tratamentos (Tabela 1). Isso mostra uma certa tolerância do milho aos herbicidas pós-emergentes aplicados. No entanto, o peso de espigas e a produtividade foram afetados (Tabela 2). 
TABELA 1. Área foliar e matéria seca de plantas de milho nos diferentes tratamentos estudados, no ensaio de 1994/95. Sete Lagoas, MG.

\begin{tabular}{|c|c|c|}
\hline Tratamentos & Área foliar $\left(\mathrm{cm}^{2}\right)$ & Matéria seca $(\mathrm{g})$ \\
\hline Cyanazine + Simazine + Assist $(4 \mathrm{~F})$ & $3.760^{1} \mathrm{~A}$ & $136^{1} \mathrm{~A}$ \\
\hline Cyanazine + Simazine (4 F) & $3.937 \mathrm{~A}$ & $129 \mathrm{~A}$ \\
\hline Cyanazine + Simazine + Assist (6 F) & $3.577 \mathrm{~A}$ & $121 \mathrm{~A}$ \\
\hline Cyanazine + Simazine $(6$ F) & $4.119 \mathrm{~A}$ & $139 \mathrm{~A}$ \\
\hline Paraquat + Extravon $\left(\right.$ Jato $1^{0}$ par $\left.12 \mathrm{~F}\right)$ & $3.889 \mathrm{~A}$ & $135 \mathrm{~A}$ \\
\hline Paraquat + Extravon $\left(\right.$ Jato $3^{0}$ par $\left.12 \mathrm{~F}\right)$ & $3.303 \mathrm{~A}$ & $120 \mathrm{~A}$ \\
\hline Ametryn + Assist (Jato $1^{0}$ par $\left.12 \mathrm{~F}\right)$ & $4.150 \mathrm{~A}$ & $130 \mathrm{~A}$ \\
\hline Ametryn + Assist $\left(\right.$ Jato $3^{0}$ par $\left.12 \mathrm{~F}\right)$ & $3.678 \mathrm{~A}$ & $119 \mathrm{~A}$ \\
\hline Retirada manual $1^{0}$ par $(12 \mathrm{~F})$ & $4.236 \mathrm{~A}$ & $155 \mathrm{~A}$ \\
\hline Retirada manual do $1^{0}$ ao $3^{0}$ pares $(12 \mathrm{~F})$ & $3.335 \mathrm{~A}$ & $111 \mathrm{~A}$ \\
\hline Testemunha com capina & $3.834 \mathrm{~A}$ & 146 A \\
\hline Testemunha sem capina & $3.704 \mathrm{~A}$ & $131 \mathrm{~A}$ \\
\hline F tratamento & $1,24^{\mathrm{ns}}$ & $0,80^{\mathrm{ns}}$ \\
\hline C.V. $(\%)$ & 14,41 & 20,14 \\
\hline d.m.s. & 1.373 & 65,9 \\
\hline
\end{tabular}

${ }^{1}$ Médias seguidas pela mesma letra não diferem estatisticamente entre si, ao nível de 5\% de probabilidade pelo teste de Tukey.

TABELA 2. Peso de espigas e grãos de plantas de milho nos diferentes tratamentos estudados, no ensaio de 1994/95. Sete Lagoas, MG.

\begin{tabular}{|c|c|c|}
\hline Tratamentos & Peso de espigas (kg/ha) & Produtividade (kg/ha) \\
\hline Cyanazine + Simazine + Assist (4 F) & $6.617^{1} \mathrm{AB}$ & $5.416^{1} \mathrm{AB}$ \\
\hline Cyanazine + Simazine (4 F) & $5.405 \mathrm{AB}$ & $4.350 \mathrm{AB}$ \\
\hline Cyanazine + Simazine + Assist (6 F) & $7.031 \mathrm{~A}$ & $5.764 \mathrm{~A}$ \\
\hline Cyanazine + Simazine (6 F) & $6.728 \mathrm{AB}$ & $5.475 \mathrm{AB}$ \\
\hline Paraquat + Extravon $\left(\right.$ Jato $1^{0}$ par, $\left.12 \mathrm{~F}\right)$ & $5.731 \mathrm{AB}$ & $4.619 \mathrm{AB}$ \\
\hline Paraquat + Extravon $\left(\right.$ Jato $3^{0}$ par, $\left.12 \mathrm{~F}\right)$ & $5.787 \mathrm{AB}$ & $4.695 \mathrm{AB}$ \\
\hline Ametryn + Assist (Jato $1^{0}$ par, 12 F) & $6.034 \mathrm{AB}$ & $4.883 \mathrm{AB}$ \\
\hline Ametryn + Assist $\left(\right.$ Jato $3^{0}$ par, $\left.12 \mathrm{~F}\right)$ & $5.534 \mathrm{AB}$ & $4.516 \mathrm{AB}$ \\
\hline Retirada manual $1^{0}$ par $(12 \mathrm{~F})$ & $5.959 \mathrm{AB}$ & $4.794 \mathrm{AB}$ \\
\hline Retirada manual $1^{0}$ ao $3^{0}$ pares $(12 \mathrm{~F})$ & $5.502 \mathrm{AB}$ & $4.432 \mathrm{AB}$ \\
\hline Testemunha com capina & $5.747 \mathrm{AB}$ & $4.670 \mathrm{AB}$ \\
\hline Testemunha sem capina & $5.137 \quad \mathrm{~B}$ & $4.126 \quad \mathrm{~B}$ \\
\hline $\mathrm{F}$ tratamento & $3,06^{*}$ & $3,00^{*}$ \\
\hline C.V. $(\%)$ & 11,14 & 11,89 \\
\hline d.m.s. & 1.653 & 1.430 \\
\hline
\end{tabular}

${ }^{1}$ Médias seguidas pela mesma letra não diferem estatisticamente entre si, ao nível de $5 \%$ de probabilidade pelo teste de Tukey. 
A aplicação de Cyanazine + Simazine + Assist propiciou o maior peso de espigas e de grãos, enquanto que a testemunha sem capina foi o pior tratamento, o que demonstra que o efeito de matocompetição foi maior do que os possíveis danos causados pela fitotoxidade dos herbicidas. Os demais tratamentos situaram-se em uma posição intermediária com relação a estas características.

A aplicação dos herbicidas cyanazine + simazine, com e sem Assist, no período de desenvolvimento de quatro folhas da cultura além de proporcionar um bom controle das plantas daninhas, não prejudicou o desenvolvimento do milho. Apesar das folhas baixeiras terem sido pulverizadas diretamente, resultando com isso sintomas visuais de necrose e perda de área foliar verde, as plantas de milho foram capazes de compensar essa perda e ainda alcançar um bom rendimento de grãos, devido à redistribuição de carboidratos acumulados na planta, conforme explicou Magalhães et al. (1998).

A área foliar é uma característica importante para se determinar o tamanho da fonte supridora de fotoassimilados (Magalhães et al., 1995). Uma redução na área foliar pode acarretar problemas para a planta durante o período de enchimento de grãos, uma vez que as folhas juntamente com o colmo são a principal fonte para satisfazer, neste período, a alta demanda dos grãos (Magalhães \& Jones 1990b e Magalhães et al. 1998). MacKinnon (1979), confirmando os dados experimentais de Allison \& Watson (1966) e Magalhães et al. (1999), concluiu que, em condições desfavoráveis, como as de alguns tratamentos do trabalho, o colmo mostra maior participação do que em ambientes favoráveis, ou seja, maior quantidade de fotoassimilados é alocado do colmo para o grão em situação de estresse, onde as folhas são menos saudáveis.

Com relação aos efeitos da retirada mecânica das folhas comparada aos tratamentos químicos, foi verificado nesse ano agrícola que, praticamente não houveram diferenças tanto nas características de crescimento como nas características de produtividade (Tabelas 1 e 2). O fato da retirada mecânica das folhas não ter afetado o desenvolvimento da planta e a produtividade discorda do trabalho de Fancelli (1988); acredita-se no entanto que o genótipo estudado no presente trabalho, BRS 3123, o qual tem características de material tropical, seja a principal razão para o resultado encontrado. Germoplasmas tropicais geralmente são limitados pelo dreno e não pela fonte de fotoassimilados (Tollenaar, 1977, Magalhães et al., 1998 e Magalhães et al., 1999).

No ano agrícola 1995/96 as variáveis avaliadas no período de floração do milho (área foliar e a matéria seca das plantas) apresentaram diferenças estatisticamente significativas (Tabela 3). Verificou-se um melhor desenvolvimento das plantas com a aplicação de cyanazine + simazine com e sem óleo mineral aplicados nos estádios de 4 e 6 folhas. A aplicação de paraquat+extravon; ametryn+assist no estádio de 12 folhas provocou injúrias que resultaram na redução de área foliar e matéria seca das plantas. As parcelas testemunhas sem capina, devido ao efeito da competição pelas plantas daninhas, apresentaram também redução da área foliar e da matéria seca de plantas.

A análise da produção de espigas e de grãos (Tabela 4) mostrou no entanto, que houve uma reversão, sendo os melhores resultados obtidos com aplicação do paraquat+extravon e ametryn+assist, apesar das injúrias observadas. Salienta-se que a aplicação desses herbicidas, apesar de causar perda de área foliar verde e matéria seca, proporcionou um bom controle de plantas daninhas no final do ciclo da cultura. $\mathrm{O}$ milho foi capaz de recuperar-se, através da redistribuição de fotoassimilados acumulados na planta e alcançar bom rendimento de grãos. A retirada mecânica das folhas, quando comparada a maioria dos tratamentos químicos, afetou somente a área foliar, quando aquele tratamento foi imposto no estádio de 12 folhas (retirando-se o $1^{\circ}$ ao $3^{\circ}$ pares, Tabela 3 ). No entanto para a matéria seca das plantas, esse mesmo efeito já não foi observado (Tabela 3 ). 
TABELA 3. Área foliar e matéria seca de plantas de milho para os diferentes tratamentos estudados, no ensaio de 1995/96. Sete Lagoas, MG.

\begin{tabular}{lcc}
\hline Tratamentos & Área foliar $\left(\mathrm{cm}^{2}\right)$ & Matéria seca $(\mathrm{g})$ \\
\hline Cyanazine + simazine + assist (4F) & $4.443^{1} \mathrm{BCD}$ & $161^{1} \mathrm{AB}$ \\
Cyanazine + simazine (4f) & $4.964 \mathrm{~A}$ & $158 \mathrm{AB}$ \\
Cyanazine + simazine + assist (6F) & $4.665 \mathrm{ABC}$ & $168 \mathrm{AB}$ \\
Cyanazine + simazine (6 F) & $4.517 \mathrm{ABCD}$ & $157 \mathrm{AB}$ \\
Paraquat + extravon ( jato $\left.1^{\circ}, 12 \mathrm{~F}\right)$ & $4.246 \mathrm{CDE}$ & $147 \mathrm{BC}$ \\
Paraquat + extravon ( jato 3 ${ }^{\circ}$ par, 12F) & $3.930 \mathrm{EF}$ & $141 \mathrm{BC}$ \\
Ametryn + assist (jato $1^{\circ}$ par, 12F) & $4.122 \mathrm{DE}$ & $151 \mathrm{AB}$ \\
Ametryn + assist (jato $3^{\circ}$ par, 12F) & $4.257 \mathrm{CDE}$ & $138 \mathrm{BC}$ \\
Retirada de folhas $\left(1^{\circ}\right.$ par, 12F) & $4.821 \mathrm{AB}$ & $188 \mathrm{~A}$ \\
Retirada de folhas $\left(1^{\circ}\right.$ ao 3 ${ }^{\circ}$ par, 12F) & $4.209 \mathrm{CDE}$ & $174 \mathrm{AB}$ \\
Testemunha com capina & $4.289 \mathrm{CDE}$ & $160 \mathrm{AB}$ \\
Testemunha sem capina & $3.454 \mathrm{~F}$ & $111 \mathrm{C}$ \\
\hline F tratamento & $5,44^{*}$ & $2,21^{*}$ \\
C.V. $(\%)$ & 8,02 & 17,08 \\
d.m.s. & 501 & 38,10 \\
\hline
\end{tabular}

${ }^{1}$ Médias seguidas pela mesma letra não diferem estatisticamente entre si ao nível de $5 \%$ de probabilidade pelo teste de Tukey.

TABELA 4. Peso de espigas e grãos de plantas de milho para os diferentes tratamentos estudados no ensaio de 1995/96. Sete Lagoas, MG.

\begin{tabular}{|c|c|c|}
\hline Tratamentos & Peso de espiga $(\mathrm{kg} / \mathrm{ha})$ & Produtividade $(\mathrm{kg} / \mathrm{ha})$ \\
\hline Cyanazine + simazine + assist $(4 \mathrm{~F})$ & $7.279^{1} \mathrm{~B}$ & $6.283^{1} \mathrm{~B}$ \\
\hline Cyanazine + simazine $(4 \mathrm{~F})$ & $7.768 \mathrm{AB}$ & $6.755 \mathrm{AB}$ \\
\hline Cyanazine + simazine + assist $(6 \mathrm{~F})$ & $8.032 \mathrm{AB}$ & $6.922 \mathrm{AB}$ \\
\hline Cyanazine + simazine $(6 \mathrm{~F})$ & $8.226 \mathrm{~A}$ & $7.084 \mathrm{~A}$ \\
\hline Paraquat +extravon (jato $1^{\circ}$ par, $12 \mathrm{~F}$ ) & $8.449 \mathrm{~A}$ & $7.322 \mathrm{~A}$ \\
\hline Paraquat +extravon (jato $3^{\circ}$ par, $12 \mathrm{~F}$ ) & $8.366 \mathrm{~A}$ & $7.170 \mathrm{~A}$ \\
\hline Ametryn + assist (jato $1^{\circ}$ par, $\left.12 \mathrm{~F}\right)$ & $8.106 \mathrm{AB}$ & $7.199 \mathrm{~A}$ \\
\hline Ametryn + assist (jato $3^{\circ}$ par, $12 \mathrm{~F}$ ) & $8.428 \mathrm{~A}$ & $6.998 \mathrm{AB}$ \\
\hline Retirada de folhas $\left(1^{\circ}\right.$ par, $\left.12 \mathrm{~F}\right)$ & $8.174 \mathrm{AB}$ & $6.954 \mathrm{AB}$ \\
\hline Retirada de folhas $\left(1^{\circ}\right.$ ao $3^{\circ}$ par, $\left.12 \mathrm{~F}\right)$ & $7.580 \mathrm{AB}$ & $6.567 \mathrm{AB}$ \\
\hline Testemunha com capina & $8.293 \mathrm{~A}$ & $7.125 \mathrm{~A}$ \\
\hline Testemunha sem capina & $5.947 \mathrm{C}$ & $5.084 \mathrm{C}$ \\
\hline F tratamento & $6,49 * *$ & $7,27 * *$ \\
\hline C.V. $(\%)$ & 7,05 & 6,67 \\
\hline d.m.s. & 1.389 & 1.132 \\
\hline
\end{tabular}

${ }^{1}$ Médias seguidas pela mesma letra não diferem estatisticamente entre si ao nível de $5 \%$ de probabilidade pelo teste de Tukey. 
Com relação as características de produção, não foram verificados nenhum efeito estatisticamente significativo dos tratamentos de retirada mecânica das folhas. A performance das plantas nesses tratamentos foi semelhante aos dos tratamentos químicos. Os comentários realizados anteriormente para o ano agrícola 1994/95 são válidos para esse ano agrícola.

A aplicação de herbicidas em pósemergência na fase inicial da cultura, além de proporcionar um bom controle das plantas daninhas, não afetou o desenvolvimento do milho.

$\mathrm{Na}$ aplicação dirigida, apesar de as folhas baixeiras terem sido pulverizadas diretamente, ocasionando com isso sintomas visuais de necrose e perda de área foliar verde, as plantas de milho foram capazes de compensar essa perda e ainda alcançar um bom rendimento de grãos, através da redistribuição de carboidratos acumulados na planta.

\section{AGRADECIMENTOS}

A José Eduardo Filho, Assistente de Pesquisa e a José Rubens de Oliveira, Técnico Agrícola da Embrapa Milho e Sorgo pela colaboração na coleta de dados.

\section{LITERATURA CITADA}

ADELANA, B.O.; MILBOURN, G.M. The growth of maize. II. Dry matter partition of three maize hybrids. J. Agric. Sci., v. 78, p. 73-78, 1972.

ALLISON, J.C.S.; WATSON, D.J. The production and distribution of dry matter maize after flowering. Ann. Bot. v. 30, p. 365-381, 1966.

DUNCAN, W.G.; WILLIANS, W.S.; LOOMIS, R.S. Tassels and the productivity of maize. Crop Sci., v. 7, p. 37-39, 1967.

\section{FANCELLI, L.A. Influência do desfolhamento}

no desempenho de plantas e de sementes de milho (Zea mays L.). Piracicaba: USP/ESALQ, 1988. 172 p. Tese de doutorado.

JONES, R.J.; SIMMONS, S.R. Effects of altered source sink relation on growth of maize kernels. Crop Sci., v. 23, p. 129-134, 1983.

LUCAS, E.O. Remobilization of stem assimilates in maize varieties grown under tropical conditions. Maydica, v. 26, n.4, p. 287-92, 1981.

MacKINNON, J.C. Energy allocation during growth of six maize hybrids in Nova Scotia. Can. J. Pl. Sci., v. 59, p. 667-77, 1979.

MAGALHÃES, P.C.; JONES, R. Aumento de fotoassimilados sobre os teores de carboidratos e nitrogênio em milho. Pes. Agropec. Bras., v. 25, n. 12, p. 1755-1761, 1990a.

MAGALHÃES, P.C.; JONES, R. Aumento de fotoassimilados na taxa de crescimento e peso final dos grãos de milho. Pes. Agropec. Bras., v. 25, n. 12, 1747-1754, 1990b.

MAGALHÃES, P.C.; DURÃES, F.O.M.; PAIVA, E. Fisiologia da planta de milho. Sete Lagoas: EMBRAPA-CNPMS, 1995. 27 p. (EMBRAPA-CNPMS. Circular Técnica, 20).

MAGALHÃES, P.C.; DURÃES, F.O.M.; OLIVEIRA, A. C. de. Efeitos do quebramento do colmo no rendimento de grãos de milho. Cienc. Agrotec., v. 22, n. 3, p. 279-289, 1998.

MAGALHÃES, P.C.; DURÃES, F.O.M.; OLIVEIRA, A. C. de.; GAMA, E. E. G. Efeitos de diferentes técnicas de 
despendoamento na produção de milho. Sci. Agric., v. 56, n. 1, p. 77-82, 1999.

MILHO: em grão $-1^{\mathrm{a}}$ safra. Levantamento Sistemático da Produção Agrícola, Rio de Janeiro, v.6, n.4, p. 38-40, 1998.

RESENDE, M.; FRANÇA, G.E.; ALBUQUERQUE, P.E.P.; ALVES, V.M.C. O momento de irrigar a cultura do milho de inverno na Região Sudeste. In: CONGRESSO NACIONAL DE MILHO E SORGO, 19, Porto Alegre. Anais... Porto Alegre: ABMS, p. 144, 1992.

SILVA, J. B. da; RODRIGUES, M. A. T.;
BEGLIOMINI, E. Indicações para o controle de plantas daninhas na cultura do milho em pós-emergência com o herbicida Sanson 40 SC e sua mistura $1+2$ com atrazine. O Ruralista, v.35, n.440, p.9-11, 1998.

TOLLENAAR, M. Sink source relationships during reproductive development in maize. A Review. Maydica, v. 22, p. 49-75, 1977.

TOLLENAAR, M.; DAYNARD, T.B. Effect of defoliation on Kernel development in maize. Can. J. Pl. Sci. v. 58, p. 207.212, $1978 b$. 